\title{
Genetic structure of the ampelographic collection maintained in the Dagestan experimental station of VIR revealed by microsatellite analysis
}

\author{
M.M. Agakhanov ${ }^{1 *}$, V.A. Volkov² , E.K. Potokina ${ }^{1,2}$ \\ ${ }^{1}$ Vavilov Institute of Plant Genetic Resources (VIR), St. Petersburg, Russia \\ ${ }^{2}$ St. Petersburg State Forest Technical University, Russia
}

DOI 10.18699/ICG-PlantGen2019-11

(c) Autors, 2019

* e-mail: gt-06.01.2015@yandex.ru

\begin{abstract}
Dagestan Experimental Station of VIR (DOS VIR, the North Caucasus) were evaluated with eight microsatellite markers that have been previously recommended for grape varietal identification. 132 alleles of the eight SSR loci were detected, their PIC varied in the range $0.63-0.87$. Four genetic clusters $(K)$ were outlined in the assessed genetic diversity. Each of the first three clusters combined grape accessions of the same geographical origin and represents a distinct ecological-geographical group - convar. orientalis Negr., convar. occidentalis Negr. and convar. pontica Negr. The fourth cluster included mainly hybrids. Key words: grape germplasm collection; ex situ; microsatellites; genetic structure.
\end{abstract}

\section{Introduction}

The genome of Vitis vinifera L. contains a huge number of polymorphic microsatellite loci, the allelic diversity of which can be used to expose the genetic structure of grape germplasm collections maintained ex situ, as well as for detection of doublets and varietal identification (Dokupilová et al., 2013).

The objective of this study was to evaluate the genetic diversity of 72 grape accessions from the ampelographic collection of the Dagestan Experimental Station of VIR (DOS VIR), which was established in 1975 and currently maintains 320 cultivated grape varieties. For the ex situ collection, the genetic assessment of the accession diversity is important since so far only the traditional methods based on morphological trait evaluation were used to recognize grape varieties. In this study, the genetic diversity of the grape germplasm collection was explored by analysis of the polymorphism of eight microsatellite loci that have been previously recommended for the purpose of varietal identification.

\section{Materials and methods}

DNA was extracted from fresh leaves using the modified CTAB-method with 2-mercaptoethanol (Rahimah et al., 2006). Analysis of microsatellite loci was carried out on the basis of PCR with the primers that were previously reported. Sizes of the amplified alleles were estimated with the Genetic Analyzer Nanofor-05 (Syntol, Russia). Frequency-based analysis (F-statistics, heterozygosity, HWE) was performed using GenAlEx 6.2 (Peakall, Smouse, 2012). To investigate the genetic diversity and the population structure of the grape germplasm collection, the software Structure 2.3.4 was employed.

\section{Results and discussion}

72 grape accessions from the DOS VIR collection were analyzed with eight microsatellite loci: scu15vv, VVS 2, VVMD 27, VVMD 31, VVIH54, VVIP31, scu11vv, and VVIB01, which had previously been recommended for varietal identification of grapes (Thomas et al., 1993; Bowers et al.,

Table 1

Polymorphism of the microsatellite loci across 72 grape accessions of the DOS VIR collection

\begin{tabular}{|c|c|c|c|c|c|c|c|c|}
\hline Loci & scu15vv & VVS 2 & VVMD 27 & VVMD 31 & VVIH54 & VVIP31 & scu11vv & VVIB01 \\
\hline No. of alleles & 9 & 14 & 13 & 11 & 18 & 28 & 25 & 14 \\
\hline Size (bp) & $182-198$ & $121-153$ & $171-212$ & $198-250$ & $143-183$ & $164-197$ & $213-293$ & $284-324$ \\
\hline Heterozygosity & 0.760 & 0.863 & 0.841 & 0.762 & 0.844 & 0.945 & 0.874 & 0.755 \\
\hline PIC & 0.835 & 0.835 & 0.753 & 0.767 & 0.671 & 0.87 & 0.630 & 0.726 \\
\hline
\end{tabular}




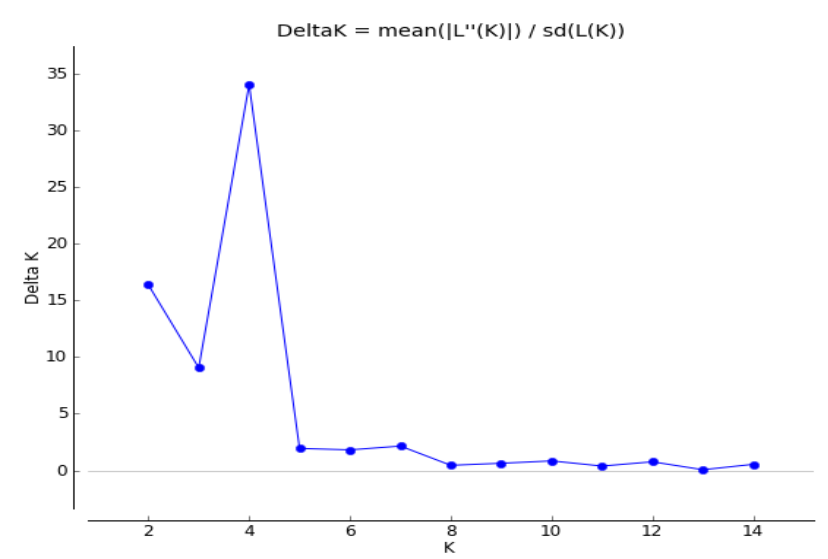

Figure 1. The most likely number of genetic clusters (K) detected within the grape genetic diversity studied.

1999). The number of detected alleles, heterozygosity (the percentage of identified heterozygotes out of the total number of plants analyzed), PIC (Polymorphic Information Content) for each microsatellite locus are presented in Table 1.

In total, 132 alleles of the eight SSR loci were detected, their PIC varied in the range $0.63-0.87$.

The probability of the number of genetic clusters $(\mathrm{K})$ among the studied accessions was estimated in the range from 1 to 5 . Ten repeats of the analysis were conducted for each $\mathrm{K}$ value. The most likely number of clusters $(\mathrm{K})$, that is, objectively isolated genetic groups in the representation studied, was determined according to the algorithm proposed by Evanno et al. (2005). Four genetic clusters (K) were outlined in the assessed genetic diversity of the grape accessions (Figure 1). Each of the first three clusters contains grape accessions of the same geographical origin and represents a distinct ecologicalgeographical group, the fourth cluster included mainly hybrids (Figure 2).

The first (red) cluster comprises 28 grape varieties that mostly belong to convar. orientalis Negr. and represent ancient Dagestan aborigine varieties. The second cluster (green) combines 18 varieties of the West-European ecogeographic group (convar. occidentalis Negr.). Among them, there were some famous grape varieties such as 'Riesling' and 'Aligoté'. The ancient autochthone grape varieties of the Black See basin (convar. pontica Negr.) were assigned to the third (blue) genetic cluster (see Figure 2).

In the ampelographic collection of the Dagestan Experimental Station of VIR, accessions of 25 grape ecotypes are maintained, including both ancient Dagestan varieties and

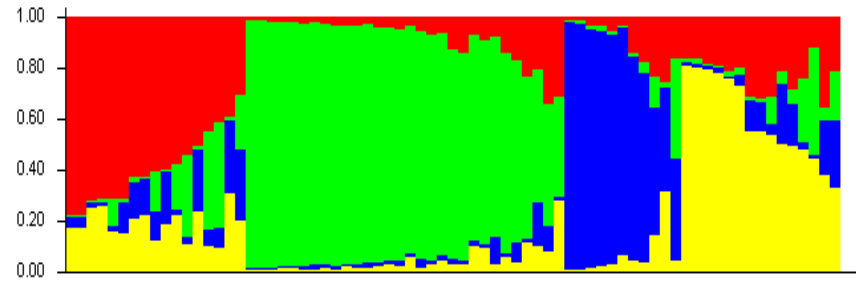

Figure 2. Structure of the genetic diversity of 72 grape accessions from the DOS VIR collection revealed with microsatellite loci.

varieties of Western European and Asian origin. The collection also contains several samples of wild-growing Vitis species which have been collected during the VIR expeditions to the Caucasus. To this day, no molecular studies have been conducted focusing on analysis of the genetic structure of this collection and its genetic diversity. Analysis of the allelic diversity of eight polymorphic microsatellite loci allowed us to evaluate the genetic structure and establish the relationship between the genotype of the grape accession and its origin.

\section{References}

Bowers J.E., Dangl G.S., Meredith C.P. Development and characterization of additional microsatellite DNA markers for grape. American Journal Enol. Viticulture. 1999;50(3);243-246.

Dokupilová I., Šturdík E., Mihálik D. Characterization of vine varieties by SSR markers. Acta Chimica Slovaca. 2013;6(2):227-234. DOI 10.2478/acs-2013-0035.

Peakall R., Smouse P.E. GenAlEx 6.5: genetic analysis in Excel. Population genetic software for teaching and research-an update. Bioinformatics. 2012:28;2537-2539. DOI 10.1093/bioinformatics/bts460.

Rahimah A.B., Cheah S.C., Rajinder S. Freeze-drying of oil palm (Elaeis guineensis) leaf and its effect on the quality of extractable DNA. J. Oil Palm Res. 2006;18:296-304.

Thomas M.R., Scott N.S. Microsatellite repeats in grapevine reveal DNA polymorphisms when analysed as sequence-tagged sites (STSs). Theoretical Applied Genetics. 1993;86(8):985-990.

Acknowledgements. The work is supported by the government program of the Ministry of Science and Education of Russian Federation, project No. AAAA-A19-119013090158-8.

Conflict of interest. The authors declare no conflict of interest. 